\title{
A COMPARATIVE LOOK AT VALUES AND RIGHTS: WHAT CULTURAL DIFFERENCES CAN TEACH US
}

\author{
F. Pearl Eliadis \\ President, Ontario Human Rights foundation
}

In this paper, I explore issues of values and rights. The paper is about how the cultural differences between all of us as citizens, immigrants, neighbours, parents or co-workers can be understood as dialogue about culture rather that fights over rights. The conflict, real or perceived, between values and rights is a topical issue in Canada.

Canada's issues cannot be viewed apart from a larger set of issues in international relations. Because of this, the role that international law has played in structuring this important debate will also be examined.

Canada's traditionally generous approach to multiculturalism has made this country a good place for new arrivals from a wide range of backgrounds. Here they can raise families and build a life without losing their cultural identities. As a child of immigrants to Canada, it is distressing to me that in recent years it has become fashionable to criticize newcomers by questioning their commitment to Canada or by asking if "foreign" values have a place in Canada. The rising voices of intolerance sometimes drown out the more moderate voices, and the result is a sort of "social blinkering" that leads otherwise sensible people to prohibit Muslim girls from wearing head scarves at school or Sikh men from wearing turbans in the RCMP.

The argument, typically, goes along the lines that these newer arrivals to our country must "fit in" and reflect the Canadian values and culture. Paradoxically, "culture" is viewed by many Canadians as inherently alien, possibly menacing and definitely something that socalled "non-ethnic" Canadians think that they do not really have themselves. Canadians frequently say that there is no such thing as a Canadian "culture" or Canadian "values." It is not clear to me why some Canadians think this way, but it may be a similar phenomenon to the view expressed by Canadians from time to time about their own accents. I have heard it said, in all seriousness, that the Canadian way of speaking English is "neutral." Canadians therefore have no accent: everyone else does. Canadians somehow occupy a neutral place in the universe of speech, dangling mid-Atlantically somewhere between Americans, English and Australians who have "real" accents. Some of us, notably white, European-stock Canadians - and I would emphasize 
that I am focusing on anglophones - think the same way about culture. Canadians have traditionally entertained a rather bland perspective of their national identity, cherishing a sense of themselves as the benign custodians of value-neutral social structures.

Of course, this is nonsense. Over the last decade, relatively high numbers of new immigrants have come from countries other than the traditional European sources and their demands sometimes provoke heretofore unheard of concerns about the loss of Canadian identity and "values." The new demographics in Canada have brought values and rights, and the possibility of serious conflict between them, into sharp focus. The emergence of these concerns is, in my view, strong evidence that most Canadians do indeed have a strong sense of a national "self." But because we have little idea of who that "self" is, or what the relationship is between our values and constitutionally protected rights, there is confusion about what exactly is at stake.

Let me first sketch what I mean by "value" and "right". These definitions are necessarily informed by my own training as a lawyer and my involvement in human rights work. My perspective is Western in bias and pragmatic in focus. This lecture will focus on the "higher order" bundle of rights called human rights, and so the working definition used here does not purport to be exhaustive.

By right, I mean that group of primary or core principles that establishes the relationship between individuals and the State. These usually take the form of a claim which may be made by an individual against the State. In the context of human rights, the term "rights" also refers to that group of claims considered to be fundamental and which is grounded in an understanding of what is fair in free and democratic societies. These claims include the fundamental freedoms (freedom of religion, association, and speech, for example), the legal rights (the right to counsel, the right to be free from unreasonable search and seizure), mobility rights and equality rights, to name a few. These rights are necessarily overreaching principles: they shape the shifting and often conflicting relations between the individual, the community and the State. They are both normative and universal.

A classic philosophical model describing how core rights are developed is found in the definitive work of John Rawls, in the Theory of Justice. Rawls describes a hypothetical exercise of constructing society's rules through what he calls the "original position."! The original position requires an abstraction of the person from the self 2 because the person making the rules is not permitted to know his or her race, age, ethnic origin, religious affiliation, etc. when making the 
rules that govern society's workings. Rawls' theoretical constructs remain enormously insightful and intuitively appealing because the rule-maker, however self-interested, is unable to ascertain his or her personal identity or to establish what his or her vested interests will be. The rule-maker is thereby forced to proceed on a nondiscriminatory basis to develop an authoritative model of rights.

By values, I mean the group of principles that directs our behaviour in our communities. They are standards, but they are frequently normative only within a particular community, culture, or social unit. For the purposes of this discussion, values may be described as the principles we use to help us establish the "good life" in our society. They include preferences in family structures, gender roles, manners and aesthetic ideals.

An easy example is the western notion of "family values" which most of us recognize as the nineties' neo-conservative call to arms heterosexual arms that embrace the traditional nuclear family as the basic social unit. "Family values" are values par excellence: they are strongly held by some, they are powerfully conformist, but they are not shared by all groups in society, notably gays, lesbians and single mothers.

Scepticism about using values instead of rights as the basis for the organizing principles of society is central to western democratic thought. Certain moral values are so incendiary that they are rooted right out of the political arena. This is achieved, at least in part, by the division of Church and State in countries like the U.S. and the United Kingdom. The story of what happens when values and moralism creep back into the political arena is, in my view, a cautionary tale. I am thinking of not only of Christian and Muslim fundamentalism or white supremacy, which are easy examples of groups trying to impose value preferences, but also of political correctness, which in its extreme form, is a good example of what can go wrong when institutions diminish rights in order to impose value structures on unwilling subjects.

Readers familiar with the international dialogue around rights, cultures and values will know that some countries reject "rights language" altogether as an attempt to impose western values on other cultures. This creates a problem for western liberals who are unsure how to respond to the strong defence of cultural legitimacy. The origins of this debate in international law are found at least as early as the Universal Declaration of Human Rights in 1948. Academics and critics from the South frequently criticize the Universal Declaration as a 
western reflection of imperialist culture imposed on fundamentally different value structures. A look at the list of authors of the Declaration belies these complaints; of the nine authors, only two (Roosevelt and Cassin) were from the developed west. Two more were from the Communist block, one from China, one from South America, and the rest from less developed nations including India, the Philippines and Egypt.

Even if these complaints are not well grounded in the U.N.'s history, the hostility of these countries, particularly in former colonies, raises other legitimate concerns. There is a perception that the West is indifferent to other cultures except perhaps as a backdrop for tourists, and this is a more serious grievance. Effective rights implementation demands that rights be coherent and intelligible in the culture in which they seek expression. Pragmatism compels us to require more of a rights-based value structure than a mere theoretical claim to rectitude.

The importance of making a rights-based argument culturally coherent is made eloquently by Sri Lankan author Coomaraswamy who argues that traditionalists will always have the general populations' support as long as so-called "western" rights claims are not made intelligible in the context of another country's value structure or culture.

Understanding culture, in turn, requires serious attention to the laws, community practices and political forces that bind individuals to society. It also means, perhaps paradoxically, that any dialogue between cultures should respect deeply held beliefs and practices. even those which challenge our own views.

In some circumstances, a serious analysis of competing values and rights reveals such a serious infringement of rights that no compromise position will be possible. Obvious historical examples range from national socialism to female genital mutilation. Short of these easy cases, it is more difficult to assess a cultural claim when a group alleges that the rights claim is so inimical to its culture that the very fabric of its society is threatened or at least weakened.

For example, a genuine conflict arises when a particular value preference (for example, women occupying traditional, subservient roles) is in conflict with a right (for example the right to be considered equal before the law). When the value is imposed by those in power on those who do not share the value, though, it is arguable that the rights claim should defeat or trump the value preference in the political sphere. The problem with this solution is that it requires a 
confrontational approach to the conflict that usually creates more problems than it solves, unless third parties are prepared to mediate the conflict or apply by political pressure or military force. Leaving aside the traditional bugbears of national sovereignty, recent experience in the former Yugoslavia and in central Africa have shown us the limited ability of international forces to broker peace or use military force in an effective way even in the most desperate circumstances.

Failing international consensus and will to interfere, a better solution lies in the power of dialogue coupled with international nonmilitary pressure. It is generally recognized in human rights circles that inter-cultural dialogue is a critical tool for resolving rights and values conflict. Simply put, meaningful and peaceful change can arguably be effected through dialogue and open debate, even in nondemocratic governments, provided international attention and pressure are sustained. The result can be a change in social order and in legal structures. The recent, albeit fragile, peace in Northern Ireland and the astonishing developments in South Africa and Myanmar are a testament to the power of this idea. 3

Engaging in dialogue requires good faith on both sides. It means that the interlocutors must acknowledge the values of the other culture, but this acknowledgment risks of being perceived as validating the very principles that one side may strongly oppose. The Western recoil from the "cultural legitimacy" defence referred to earlier is easier to understand in this context. Nevertheless, there is no good alternative to dialogue, except in the worst or most obvious cases, and there is too much to lose through isolationism, except in the most egregious cases of duplicity or evil.

Even after some "rights" battles are won, it is still hard to tell how the war is going. This is clearest in the case of feminism, because even when rights and "bare equality" were achieved, feminist issues have remained vital and divisive to this date, and ongoing dialogue is still an important tool. Women today know that they have far more to do than they did before they were "liberated" and that employment opportunities are still restricted by demands at home. Many feminists have observed that by insisting on context-specific "equal" treatment, women are thoroughly trounced when male-dominated institutions apply "equality" rules in an apparently neutral way with no effort to address the underlying causes of systemic discrimination.

At the very least, meaningful change requires that we rethink basic assumptions about equality. Canadian author Kathleen Mahoney 
describes this in a nutshell:

Systemic discrimination or inequality of condition, the most damaging form of discrimination, cannot be addressed via the rulebased sameness of treatment approach. Indeed, the use of this model virtually makes systemic disadvantage invisible. By structuring equality around the male comparator, the assumption is made from time to time that equality exists and from time to time, individuals will be discriminated against. The persistent disadvantage women suffer across the board because of societal biases is obscured. The question then becomes, can [international human rights law] support and deliver substantive equality?4

But attempts to impose "substantive equality" through methods like affirmative action, quotas etc., have provoked hostile reactions, not only from neo-conservatives but also from the average citizen: there seem to be countless apocryphal stories about male white relatives denied gainful employment. This backlash has strengthened the hand of those have who astutely grabbed the appealing issue of nondiscrimination and used it to sustain an attack against social programs that try to level the playing field. These developments may or may not be welcome, but they do identify an important new force in the rights dialogue: the human rights backlash.

This backlash has been evident in best-selling books for several years now. Indeed, for those who have read Camille Paglia's best known polemic, Sexual Personae, it has become difficult to read anything about the role of feminist values without remembering a powerful question Paglia puts to the reader: who built human society? The answer, according to Paglia, is men: from the great buildings and bridges to the laws of physics and the definitive contributions in science, art, literature and music, the memorable moments of human history owe their existence, almost without exception, to men. Paglia's explanation for this is not exactly revolutionary in the history of thought: men's psychological behaviour shadows their sexual behaviour and so the physical vectors that propel men in two directions - upwards and outwards - lead them, so to speak, to greater things. Sexual Personae revived the old chestnut "biology is destiny."

Paglia attacks women's studies programs - and much of feminist thought generally - as little more than ghettoized fora for organized whining and the reader cannot help but be impressed by Paglia's barrage of scholarly support for her thesis, consisting of her views on pretty much everything that has ever happened in the history of 
western civilization. Paglia also criticizes feminists for their reliance on the crutch of oppression at the hands of men. If this explanation were true, she and the backlashers argue, women should be more or less equal with men in progressive Western society, at least by now. Even in our own "equal" society, Paglia implies, women are not found in anywhere near proportionate numbers in the places that matter government, politics and business. Indeed, in our industrialized society, where women can vote and work, there is still no meaningful, independent access to power for women. 5

I believe that this backlash is played out in all "rights" debates, not just in the area of women's rights. Why haven't women done better? Why haven't certain groups in society done better? And what is being done about it? Neo-conservatives ask, why push women out of their traditional roles? Why are we obliged to boost some individuals over others and why is the government called upon to aid this exercise? These are not always easy questions, but the liberals often view the issues as a rights issue (for example, the equality of women) and the neo-conservatives as an issue about values and the ways we lead our lives.

The path to resolving these conflicts lies in an attempt to assess underlying interests and the validity of the claims made by both sides to a conflict: there are at least three important mechanisms that can help us assess the validity of the values defence to a rights claim, especially in the cross-cultural and comparative context. My thesis is that if, after using these analytical tools, it appears that the values or culture defence is a mere shield being deployed to evade international standards, the rights claim should prevail. Otherwise, it should be left alone. The three tests are:

(1) the public-private divide;

(2) the harm principle, and

(3) international standards and national law.

\section{LOOKING INTO THE PUBLIC-PRIVATE CHASM}

The first test examines whether the rights claim is obscured by "public-private" divisions that are sometimes used to shield rights abuses. This defence prevents international law standards from "getting at" discriminatory treatment. Nations frequently argue that certain rights cannot be claimed because the group claiming them is subject to "private" law rules, an area immune from international 
interference. Issues affecting the rights of these groups are frequently treated as "beyond justice" simply because they take place on the private side of the schism.6

In international law, an excellent example of this tendency is the treatment of non-nationals by immigration officials. Nation states have a basic right to decide who belongs and who does not. Aliens at common law are "hors la loi" and therefore are at the mercy of the authorities who raise international prerogative to justify treatment that would be unacceptable if imposed on citizens. 7 When nations are accused of treating refugees or other aliens badly, it is usually argued that "this person is an alien and enjoys no constitutional protection."

Similarly, when Canada was criticised by both the First Nations and internationally for its treat of Aboriginal peoples, Canadian diplomats argued that native issues fell under "private law," outside the reach of international law standards.8

Women's issues are also relegated to the private realm, with the result that they are disentitled in the public sphere. A person who is invisible in public is not a full citizen in any civic sense of that term.9 Some authors go so far as to argue that women are really aliens in their own countries because genuine citizenship should subsume political participation in civic life, a participation that is effectively denied the moment women step outside their traditional roles in certain countries. Thus a married Muslim woman who lives under the laws of Shari'a is formally subject to the guardianship of her husband and is excluded from independent political life in fundamentalist countries. Women who marry a foreign national and lose their right to citizenship in the country of birth necessarily become "alien."10 Until relatively recently in Quebec, a married woman had no judicial personality and had extremely limited rights to engage in any contractual or commercial activity.

It is made startlingly clear under the public/private analysis that Aboriginals, minorities, and women, are inadequately sheltered by the myriad international legal instruments that are designed to assist them. In certain cases, however, a careful analysis will reveal that there is nothing in the cultural practice or sovereignty claim that calls out for immunity or protection. International law has, in these cases, imposed universal standards to overcome "legal defences or objectives based on local law."

\section{THE HARM PRINCIPLE}


Stepping outside the traditional boundaries of national sovereignty frequently provokes anger and violence. And this brings us to the second test for assessing the merit of a value preference as against a rights claim, the harm principle. Does the cultural practice or value result in harm to the claimant?

A strong indicator of the obstacles to an effective set of legal rights is evidence of State sanctioned or tolerated violence. Taking the example of the women's movement, the numbers are simply numbing: more women were killed in "dowry deaths" between 1988 and 1991 in India than casualties were inflicted at large in the armed conflict in the Punjab over that same time period;11 men on trial for wife murder are still successfully defended by the "defence of honour" in Latin America, 12 and, as discussed above, the availability of sex-selection is having a significant impact upon gender proportions in India and China. 13

There is a serious case for setting aside a country's attempts to protect "cuitural" practices when a group is physically harmed. Parenthetically, this is precisely what makes the abortion debate so difficult, because even the most committed pro-choice advocate knows that the harm principle is violated each time an abortion is carried out. There has been a dearth of self-criticism in the liberal "conversation" about how to respond to these new challenges. For example, most liberals are horrified by the statistics on female feticide in countries like India where the practice has reached such proportions that it has actually changed the ratio of women to men in the world's most populous democracy.14 Abhorrence of these practices is probably grounded in the fact that we recognize that killing a fetus simply because it is female is a manifestation of violence against women at its most basic level.

But the same liberals will fight hard for the right to abort a child, including a female child, simply because it poses an inconvenience for the mother at a given point in time. I do not put forward a position as to whether one cultural value (male children as opposed to a mother's self-realization) is superior to the other. But it is clear that reflexive reactions in the two cases do tell us something about the problematic conceptual footing of some so-called rights-based principles and the failure of thinking liberals to respond effectively to fair challenges.

But abortion is one of the hardest cases, and even if a rights-values debate cannot be settled effectively in that sphere, it can in others. A practical application of rights-based principles can be used in case studies such as female genital mutilation. The Muslims of forty nations 
in the Persian Gulf, the Arabian Peninsula and Africa still widely practice genital mutilation of young girls.15 Supporters justify the practice on two levels, first, as a religious imperative, and second, on the grounds of cultural legitimacy and history.

Nowhere does the Muslim Holy Book condone this practice, let alone require its universal implementation. What is left is social preference, albeit one whose gravity should not be underestimated. In certain religious communities, a young rural woman who has not been excised will not marry, will not be accepted as an adult and is a social outcast. In rural African society, this is virtually a sentence of living death. The answer, I believe, is that the practice must be halted, despite the social preference in certain areas, because of the harm principle. The right to physical integrity is a fundamental human right. The removal of a woman's genital organs, in whole or in part, is not a trivial interference with that right. In practice, therefore, the dialogue has to be engaged at least at the level of health practices rather than an argument about moral correctness. This form of dialogue engages a third test, namely that of ensuring that dialogue is preceded by familiarity with local practices, laws and culture, and gauging them against international standards.

\section{FOCUSING ON LOCAL SOLUTIONS}

Understanding local law and practice is critical to assessing the strength of rights-based claims, especially those that focus on dialogue16 as a tool for change. Leading authors from the South point out that sensitivity to history and context provides the starting point for inter-cultural dialogue. Detailed familiarity with local law and cultural practices is fundamental. A regionally specific analysis applies fundamental principles of negotiation to the exercise of understanding how a community responds to challenges to their value structures or the resources that support them. Those principles teach us that conflict resolution is optimized when each party is aware of the other side's underlying interests and familiar with the "rules" that apply.

An obvious starting point for women is the Islamic fundamentalist movement, viewed by many women as especially threatening. 17 The history of the laws of Shari'a and their development in countries such as Sudan provides a model to show how patriarchal interpretations of traditional laws have consistently appropriated the voice of religious institutions in conservative Muslim countries. 18 
Muslim law in several conservative Islamic countries deploys the practice of male guardianship over women in a striking example of how women spend their lives under a form of tutelage (gawama). Several Muslim authors opine that qawama infringes basic human rights and freedoms, it is also true, however, that there are reformers in the Muslim tradition who support the abolition of male guardianship and other repressive features of fundamentalist practice, but in a manner consistent with Islamic law.

Religious imperatives and prohibitions also weave a complex fabric around South Asian women. One of the compelling case studies is the traditional, now rare, Hindu practice of sati. In 1987 the infamous case of the sati of Roop Kanwar, an eighteen year old girl who was burned alive on the funeral pyre of her husband. was surrounded by controversy, and is still a focal point for human rights debate in India and around the world. Did she solemnly and willingly commit suicide or was she drugged or coerced? Were the Hindu clerics involved in forcing the young woman to take her own life? Should the religious overtones of the practice diminish the moral force of protests against it?19 For many authors these debates obscure what to many is the central issue of sati as a motif for the larger question that arises when women's rights confront cultural demands: what is the point of all these laws if the people do not believe that putting an eighteen year old girl on a funeral pyre... is not a denial of the most basic fundamental right - the right to life?

There are more specific difficulties with the religious justification of sati, difficulties that lie the very practical realm. Few authors point out that there is evidence that Kanwar's in-laws stood to reap a significant financial gain from the sati of their daughter-in-law. In Rajput society, a living widow may return to her own parents with her dowry. On the other hand, an immolated widow would ensure that the dowry would remain in the hands of the in-laws. This sort of information is helpful in understanding what the underlying interest may actually be. It is critical to sort out what is at stake. Moreover, if the practice is itself a violation of local law, then the legitimacy of the cultural defence is dubious. Sati was illegal in India at the time of Roop's death.

Finally, if the local laws or customs are in breach of an international standard that has been adopted, formally or otherwise, there is a much stronger case to be made for rejecting the defence based 
on custom. In such circumstances, it will be important to determine whether there is an applicable international rights standard and determine whether the country accepts the application of that standard. For example, Florence Butwega, a noted African jurist, explains in a recent article why rules of inheritance and land transfer that favour men are being dismantled because the very country seeking to impose the rules was violating the equality principles set out in the African Charter of Peoples and Human Rights which that country had ratified.20

Similar arguments have taken place around the various court cases and social conflicts around headgear. Wearing the turban is a fundamental expression of religious belief for Sikh men, one of the imperative "five K's." I believe that this is a rights issue, based in freedom of religion. Members of Legion Halls or other organizations who opposed the wearing of the turban argued two things, one serious, one less serious.

The less serious argument was that the Stetson is a part of Canada's history that the RCMP force is identified through its uniform and that therefore the Sikh should not be permitted to wear a turban. Leaving aside the fact that there is no intelligible right being invoked here, no one who has ever seen a Mountie in uniform would ever mistake a turban-wearing Sikh mountie for, say, a pizza delivery man. The good faith of these arguments is always undermined by the dominant group's exceptions for itself: readers will recall that in certain Canadian legion halls, Sikh men were barred from entering the Legion halls because the rule was that a man must remove his head covering as a respect for God or fallen comrades. This argument disintegrated utterly when it was discovered that Legion Hall members were wearing baseball caps during important games.

The more serious argument was the separation of Church and State. The argument from principle is that the State cannot be seen to favour one religion over another, and that the breach of the uniform code amounts to an official endorsement of the Sikh religion by the State. The problem with this argument is that it is simply untrue. The State is not endorsing any particular religion. Any other legitimate and equally compelling directive in another religion respecting the wearing of headgear would also be respected, according to a judgment of the Federal Court of Appeal. All we are left with is a religious freedom argument, grounded in the Charter and international law standards, against a value preference of no headgear. Thankfully, the Federal Court of Appeal unanimously supported the Sikhs' position. 
Values create bonds, trust and give us a sense of where we stand in our communities, as well as what is expected of us. As in all relationships, the relationship and dialogue between human rights and the cultural community in which they seek expression must be governed by an understanding that is sensitive to context. Both rights and values are tools that allow us to live in harmony with each other. They are supposed to enrich our lives and teach us to value each other as human beings. The accusation that a right is damaging to a cherished way of life, therefore, must be taken seriously. But authors, argue, that "the argument from cultural relativity or cultural diversity cannot be used to undermine or evade human rights obligations." 21 Finding the balance in these tensions and a proper role for dialogue will be the challenge for human rights in the twenty-first century.

\section{REFERENCES}

1. John Rawls, A Theory of Justice (1972).

2. A process that is vigorously attacked by communitarian philosophers like Charles Taylor.

3. The recent release of Aung San Suu Kyi and her subsequent call for peaceful dialogue provide compelling evidence of the power of this approach.

4. Cook, supra note at 11-12, also at 445 .

5. Some of the best books on this topic are not law books, they are business books. See Harragan, Games Mother Never Told You (Wamer Books: New York, 1977).

6. Romany, "State Responsibility Goes Private: A feminist critique of the public/private distinction in international human rights law," in Cook, supre note 185 at 95, note 45.

7. The recent decision of the Supreme Court of Canada in Deghani v. Minister of Employment and Immigration is the bast Canadian example.

8. See, e.g., Sanders, "Remembering Deskaheh: Indigenous Peoples and International Law" in Cotler and Eliadis, eds., Intemational Human Rights Law: Theory and Practice (Canadian Human Rights Foundation: Montreal, 1992) at 485.

9. See Romany, "State Responsibility Goes Private: A Feminist Critique of the Public/ Private Distinction in International Human Rights Law" in Cook, supra note 1 at 85.

10. See the Unity Dow case, discussed by Chaloka Beyani in "A More Effective Guarantee in the African System" in Cook, supra note 1284 at 295.

11. Globe and Mail , n.d. (15.891 compared to 14.500).

12. Although appellate courts in Brazil have not accepted the "defence of honour ," so called because of the justification pleaded by husbands believing themselves to have been 
cuckolded, lower courts are still accepting the defence. Discussed by Romany, Roth and Fitzpatrick.

13. There is some evidence that Korea follows similar patterns, except that the use of sex-selection techniques and the abortion of female fetuses appears restricted to the first child so that there are more second-child births of females.

14. In India, the falling rates of women in the population are believed to be related to violence against women in that society: Kirti Singh "Obstacles to Women's Rights in India," in Cook, supra note 1 at 389.

15. The term genital mutilation encompasses clitorectomies, female circumcision. excision and fibulation. 1991 United Nations Seminar on Traditional Practices Affecting the Health of Women and Children.

16. One influential proponent of this view is the psychologist Ashis Nandy who is well known for his analysis of the effect of colonial occupation on the psychology of the Indian people. See A. Nandy, ed. At the Edge of Psychology (New Delhi: Oxford University Press, 1980).

17. See An-Na"im. "State Responsibility under International Human Rights Law to Change Religious and Customary Laws" in Cook, supra nose 1, 167 at 181. For a recent example of how traditional Islamic practices are brought home to Canadians, on March 13, 1995 the Quebec Human Rights Commission released a study on the practice of the excision of genital organs in young Muslim girls and the practice of reinfibulation of women after childbirth.

18. Halim, "Challenges to Women's International Human Rights in the Sudan," in Cook, supra note 1 at $397,408$.

19. For an insight into Ashis Nandy's views in the context of sati, see "Sati as Profit versus Sati as Spectacle" in Hawley, ed. Sati: The Blessing and the Curse (New York: Oxford University Press, 1994) at 131.

20. Butegwa, "Using the African Charter on Human and People's Rights to Secure Women's Access to Land in Africa" in Cook, Human Rights of Women: National and International Perspectives (Philadelphia: University of Pennsylvania Press. 1994) at 495. 21. Chaloka Beyani, 'Toward a More Effective Guarantee in the African Human Rights System" in Human Rights of Women, at 285. 